\title{
San Bartolo y Cobija: Testimonios de UN MODO DE VIDA MINERO EN LAS TIERRAS ALTAS Y LA COSTA DE ATACAMA ${ }^{1}$
}

\author{
Carlos Aldunate del S. ${ }^{2}$, Victoria Castro R. ${ }^{3}$ y Varinia Varela G. ${ }^{4}$
}

\section{* INTRODUCCIÓN}

\section{Resumen}

Las vinculaciones entre costa y tierras altas de Atacama se investigan a través de dos casos de estudio que documentan un modo de vida minero que ha impregnado a la "cultura del desierto" en estas latitudes desde la prehistoria hasta hoy. San Bartolo en las tierras altas de Atacama y Cobija en la costa se caracterizan por ser enclaves asociados a una intensa red de tráfico, vinculada durante la prehistoria al acceso de los atacamas a la costa, en épocas coloniales al camino de Potosí, y después a la explotación industrial del cobre.

Palabras claves: relaciones tierras altas y costa - minería - Atacama. Abstract
Relationships between the Atacama coast and the highlands are
studied through two examples. Both of them show the mining
way of life, as characteristic of the "desert culture" in this area
since the formative prehispanic periods until now. San Bartolo, in
the cordillera, and Cobija, by the sea, are characterized as mining
settlements, part of an intense traffic network, related in prehistoric
times to the access of the atacamenians to the coast, to the silver road
of Potosí during the Colonial Period and, in the republican era, to the
industrial exploitation of copper.

Key words: relationships highlands - coast - mining - Atacama.

Recibido: noviembre 2007. Aceptado: junio 2008.
Nuestros primeros acercamientos a la minería en Atacama fueron posibles bajo el marco de un proyecto que investigaba los senderos y caminos entre Ascotán y Catarpe, cuando estudiamos el asentamiento minero de San Bartolo (Aldunate et al.2005). Hoy renovamos nuestro interés por este tema bajo nuevas perspectivas, que intentan investigar las relaciones entre la costa árida de Antofagasta y las tierras del interior, siempre dentro del marco de referencia a los paisajes culturales (Aldunate et al. 2003).

La información arqueológica yetnohistórica confirma estos vínculos establecidos con el fin de acceder a los recursos del litoral.Ya en épocas prehispánicas son abundantes las evidencias cerámicas, textiles y metalúrgicas de tierras altas que se encuentran en el litoral (Latcham 1928:43, 1936: 136; Berdichewsky 1965; Larraín 1966; Aldunate et al.2007 Ms)y, durante la Colonia, el camino de Potosí transita por estos lugares vinculando a las sociedades de ambos territorios bajo los paradigmas impuestos por la estructura de dominación colonial (Castro 1997). En la República del siglo XIX estos contactos se intensifican a causa de las explotaciones mineras de cobre, bórax, azufre y los yacimientos de guano en la costa, cuando el puerto de Cobija funcionaba como eje importante del comercio de estos productos hacia otros lugares.

\footnotetext{
${ }^{1}$ Proyecto FONDECYT 1050991: "El desierto costero y sus vinculaciones con las tierras altas. De Cobija a Calama".

2 Museo Chileno de Arte Precolombino, Bandera 361, Santiago, CHILE. Email: caldunate@museoprecolombino.cl

3 Universidad Católica del Norte. Gustavo Le Paige 380, San Pedro de Atacama, CHILE. Email: vcastrorojas@hotmail.com

4 Museo Chileno de Arte Precolombino, Bandera 361, Santiago, CHILE. Email: vvarela@museoprecolombino.cl
} 


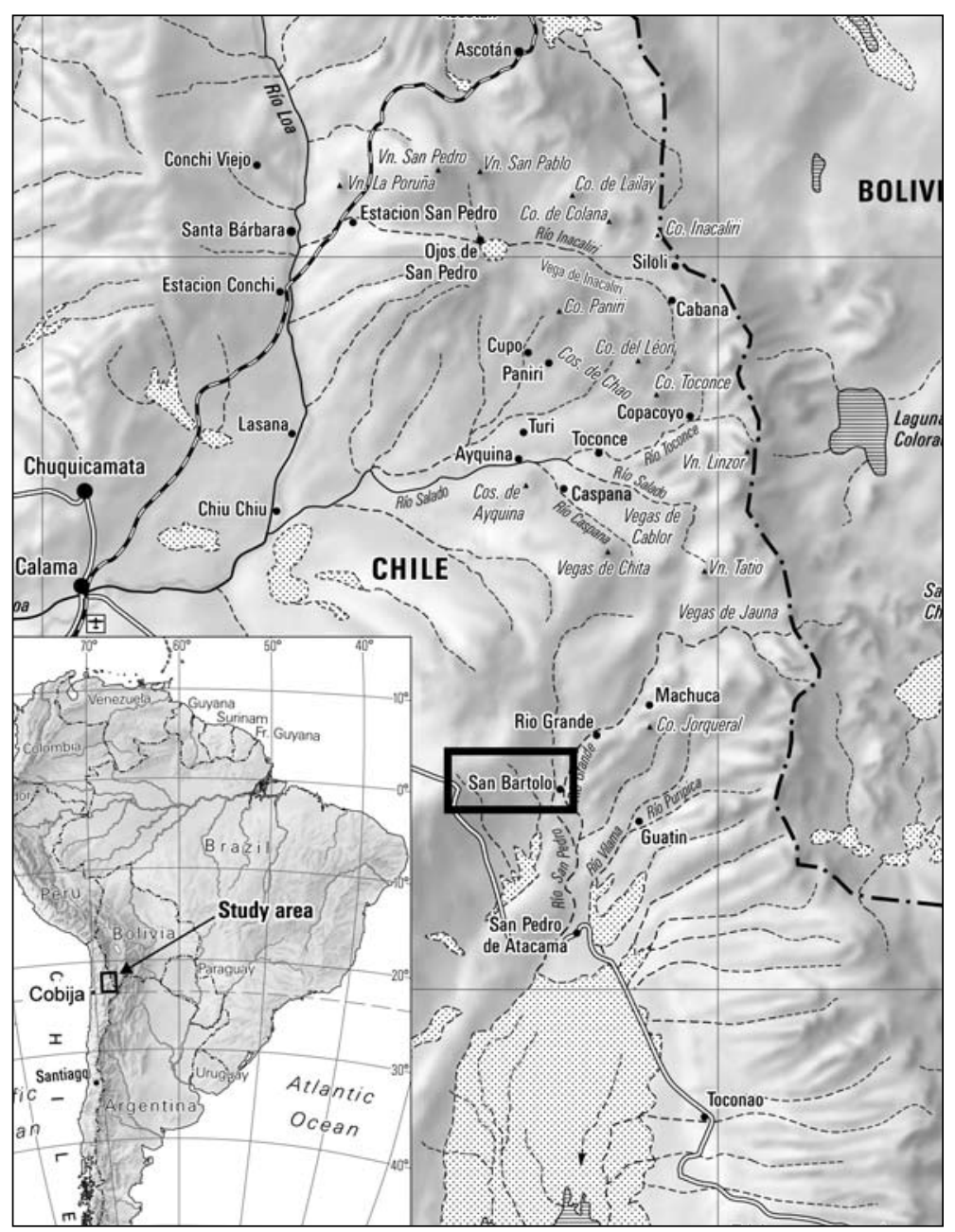

Figura 1. San Bartolo en Atacama.

Tanto en las tierras altas como en la costa hay sitios interesantes para este estudio, que desempeñaron funciones de enclaves mineros $y$, en este sentido, son testimonios de un modo de vida en Atacama desde la prehistoria hasta hoy. Abordaremos esta investigación considerando la "arqueología de la minería", propuesta teórica ofrecida por Salazar (2003-2004), siempre con el afán de vincular la información arqueológica con la histórica y etnográfica.

\section{- San Bartolo}

La localidad de San Bartolo se ubica a unos 2800 $\mathrm{m}$.snm en el valle del río Grande de Atacama, tributario del río San Pedro. Administrativamente pertenece a la provincia del Loa, región de Antofagasta, comuna de San Pedro de Atacama (Figura 1). Se trata de un sector de este valle que se ensancha en muchos meandros, dando origen a varias terrazas fluviales que hacen posible el asentamiento humano. La vegetación es escasa y está determinada por la altitud y la salinidad del agua, que se agudiza aguas abajo de la quebrada de Palicaye aportando aguas provenientes de sectores salinos que llevan minerales de cobre. Se accede a San Bartolo por un camino o sendero peatonal que sale desde el pueblo de Río Grande a $11 \mathrm{~km}$ al norte, y por un desvío del camino vehicular (B-123) que va desde San Pedro de Atacama a Río Grande, cruzando el río Salado. Por oposición al amable paisaje quebradeño propio de estas tierras altas, en San Bartolo se percibe un medio ambiente muy fuerte, aumentado por las potentes formaciones geológicas de 
la Cordillera de la Sal. Sin embargo, estas condiciones favorecieron la ocupación humana "tipo enclave" para actividades mineras durante siglos.

\section{Antecedentes arqueológicos}

Las referencias acerca de explotaciones mineras prehispánicas en San Bartolo se inician con Philippi (1860), quien en su viaje por el Desierto de Atacama en el verano de 1853-1854 advierte labores mineras precolombinas en estos yacimientos, e incluso encuentra artefactos como "combos de cobre" y una pala de madera. Latcham $(1936: 108,125)$ señala que las minas prehispánicas más conocidas de la región atacameña eran las de Chuquicamata, San Bartolo y Toconao, y que en el Museo Nacional hay dos fragmentos de puntas de hachas de cobre de esta procedencia, que se hallaron junto a escorias, haciendo presumir la existencia de guairas u hornos de fundición andinos. Este autor menciona que en San Bartolo hay minas de cobre trabajadas por los "indios precolombianos". En otra publicación Latcham (1928) describe e ilustra vasijas cerámicas de San Bartolo similares a las encontradas en Cobija. Señala también que:

“(...) en el Museo (Nacional) existen tres martillos de piedra enmangados hallados uno en Chuquicamata, uno en San Bartolo y el otro por nosotros en Quillagua. Es evidente que éstos habian servido para trabajos mineros y muestran señales de bastante uso (...)" (Latcham 1938: Fig. 33).

Instrumentos semejantes se encuentran en el contexto exhumado con el "Hombre de Cobre" (Bird 1979) y en Huantajaya. ${ }^{5}$ Núñez (1999: 181, 185) menciona a San Bartolo como uno de los yacimientos de cobre que, junto a otros del área del Salar de Atacama, justifican la alta presencia de artefactos de este metal en el Museo Arqueológico de San Pedro de Atacama; asimismo, denota este sitio como proveedor metalúrgico del centro administrativo inca de Catarpe, señalando que allí existirían probables labores de fundición local.

\footnotetext{
5 Colección Museo Chileno de Arte Precolombino.
}

\section{Antecedentes históricos}

Entre las primeras referencias a San Bartolo están las efectuadas en 1858 por Von Tschudi (Lehnert 1996) durante su viaje entre Córdoba y Cobija, quien señala que estas minas de cobre fueron trabajadas hace siglos por los "indios" y abandonadas después de la conquista española, para ser de nuevo explotadas en 1818 , año en que un inglés, M. St... (sic), adquirió las pertenencias y, con la ayuda de mineros alemanes, instaló mesas vibradoras que dieron muy buenos rendimientos. El viajero indica que de las minas se extrae cobre nativo granulado, muy fácil de trabajar con un simple lavado por medio de agua:

"El cobre se encuentra aquí solamente en estado nativo, de las formas más estrafalarias que por su aspecto imitan muy bien hojas, musgos, líquenes, arbolitos, etc., por otra parte se encuentra especialmente como la llamada barilla, es decir, cobre nativo granulado, que forma junto con la arenisca aflorante una masa compacta. Para extraer el cobre se trata pues solamente de triturar los bloques de arenisca y separar el metal de la arena. El cobre lavado y empaquetado en pequeñas bolsas se lleva a Cobija para embarcarlo. De San Bartolo pasa un camino a Calama (...)" (Lehnert 1996:12).

Este era el gran atractivo de las minas de cobre de San Bartolo. El procesamiento para extraer el metal era muy simple por encontrarse en estado nativo, en forma de charqui o de "barrilla". Con un simple proceso de molido y lavado se podía separar de la arena y tierra y obtener el metal para ser trasladado. ${ }^{6}$ Había suficiente agua en el río Grande como para hacer las labores de lavado. En esa época, la escasez de combustible para la fundición dificultaba el laboreo de las numerosas minas de la región que no tenían cobre nativo. Aquellas industrias que tenían fundición usaban el carbón de queñoa (Polylepis sp.),

\footnotetext{
${ }^{6}$ Domeyko (1898: 147) señala que "en las minas de Corocoro y las de San Bartolo de Atacama en Bolivia, el cobre forma como una arenisca de grano pequeño de cobre, de manera que molido y lavado produce una arena de cobre (barrilla)". En otra obra (1897: 202) este autor anota que el mineral de San Bartolo tiene un $76.6 \%$ de óxido de cobre, un $0.9 \%$ de óxidos de hierro y manganeso, un $18 \%$ de "carbonato de cal en venillas mui angostas (criadero)", un 1.4\% de residuos insolubles y un $3.1 \%$ de agua y pérdida.
} 
circunstancia que probablemente causó la casi total extinción de esta especie arbórea en la segunda región. ${ }^{7}$ Los yacimientos con este tipo de mineral eran escasos y el recurso se agotaba rápidamente, lo que explica el éxito de San Bartolo en sus explotaciones iniciales y sus periódicos abandonos, sumados a los continuos aluviones y el anegamiento de las minas que destruían las faenas e inundaban las instalaciones.

Philippi (1860: 60-65) en el verano de 1853-1854 viajó al Desierto de Atacama guiado por el gran explorador y buscador de minas don Diego de Almeyda (Vicuña Mackenna 1883: 226 y siguientes). En 1848 Almeyda se había asociado con otros empresarios para explotar San Bartolo, estableciendo allí un trapiche y algunas faenas. Al parecer era un yacimiento codiciado, pues había varios interesados que le disputaban este derecho. Philippi (1860) compara este mineral con el célebre Coro Coro del altiplano boliviano, y hace presente los problemas que acarrearía su explotación por la escasez de recursos para mantener trabajadores y animales de transporte, cuya traída de Chile o Argentina encarecería demasiado el producto.

Durante la segunda mitad del siglo XIX son relativamente frecuentes las menciones a San Bartolo, sobre todo antes del descubrimiento de los grandes yacimientos ${ }^{8}$, debido al auge que la producción cuprífera tiene a mediados de ese siglo a causa del precio del cobre y la competitividad de empresarios, como Agustín Edwards y Carlos Lambert, un pionero industrial francés que estableció fundiciones y produjo cobre laminado y en planchas. Después de 1879 la producción de este metal decae por varios motivos: la baja de sus precios, la Guerra del Pacífico (Vicuña Mackenna 1883:367 y siguientes) y el surgimiento de competidores como España, Estados Unidos y Australia

\footnotetext{
7 En San Antonio de Conchi había una mina y "hornos de manga", donde "se fundía con carbón de queñua. Veinticinco quintales de este combustible bastaban para fundir 50 de mineral, o sea, un cajón boliviano. Los mineros llevaban allí sus metales para ser fundidos a maquila, i se les entregaba el cobre resultante de aquella operación" (Valdés 1886: 58).

8 Vidal Gormaz (1879: 13-14); Bertrand (1885:22); San Román (1894: 349, 1896:201); Domeyko (1897: 194, 202 y 1898: 147); Herrman (1900: 163); Risopatrón (1910: 154, 1918: 175, 1924: 68).
}

(Valdés 1886: 10).9 En 1885, San Bartolo se encuentra completamente abandonado con el establecimiento de administración, el trapichey sus rudimentarias máquinas de concentración en ruinas, y "sin ningún habitante en el lugar, de quien tomar informaciones”. Además, las instalaciones habían sufrido los efectos de una gran crecida que las había inutilizado por completo (San Román 1896:159).

De acuerdo a informaciones de lugareños de Río Grande, las minas habrían sido explotadas hasta alrededor de 1930. En 1946 el Dr. Juan Brüggen (1946: 62-65) señala que, en su visita a San Bartolo, las minas estaban completamente abandonadas y la planta se hallaba en ruinas. Hemos obtenido información etnográfica que señala que posteriormente hubo algunas explotaciones esporádicas y en pequeña escala hasta 1973, fecha en que una gran crecida del río "que se lo llevó todo" habría anegado nuevamente minas e instalaciones.

Actualmente, los comuneros de Río Grande señalan que San Bartolo fue una estancia de la familia Ayavire, lo que se confirma con un topónimo de ese nombre en el ensanchamiento del valle, que aparece en un mapa de 1907 (Figura 2). ${ }^{10} \mathrm{Al}$ parecer, los mineros que explotaron estos yacimientos de cobre se apoderaron también del terreno superficial con objeto de establecer las faenas, las habitaciones de los obreros, la administración y, especialmente, para abastecer de alimentos a los habitantes y animales de carga. La población local señala que arrendaban tierras "a la Compañía" en San Bartolo para sembrar trigo, maíz, zapallos y alfalfa, productos que eran vendidos allí mismo.

El título de tierras que se acaba de entregar a la Comunidad de Río Grande y que abarca 83.601,61 ha, llega en su límite suroeste precisamente hasta el noreste de San Bartolo, sin cubrir este valle, propiedad ancestral de la familia Ayavire de Río Grande (Molina 2000). Tenemos antecedentes de que Felipe Ayavire "de San Bartolo",

\footnotetext{
9 Valdés (1886: 7-10) señala que entre 1872 y 1879 Chile exportaba un $56 \%$ del total de cobre que utilizaba Inglaterra, cifra que baja a un $45 \%$ en $1880-1881$.

10 Comisión Chilena de Límites 1907.
} 


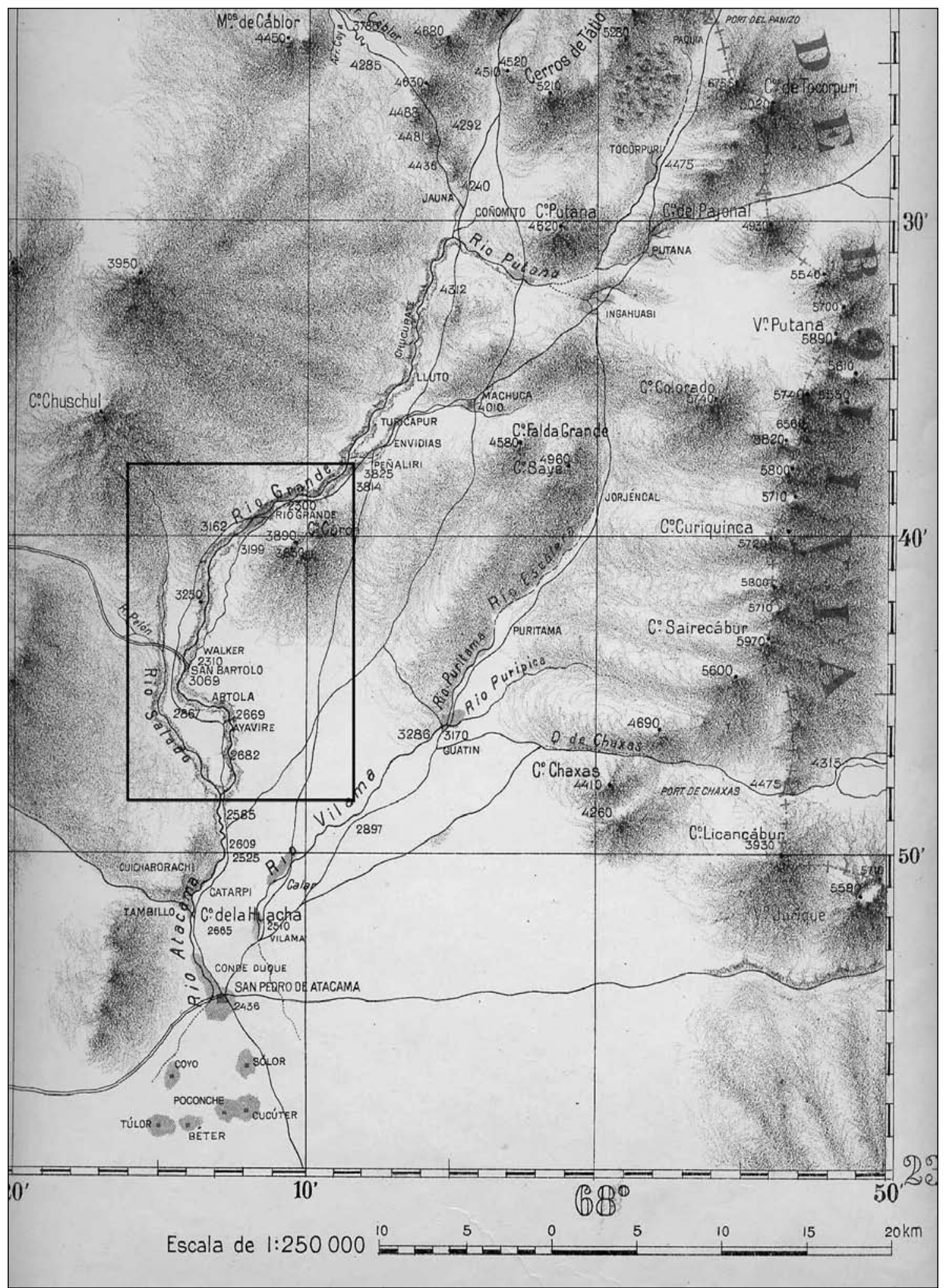

Figura 2. Fragmento Mapa de 1907 (Comisión Chilena de Límites). 
poseía una casa, un corral y una capilla en la vega de Inacaliri, situada a unos $50 \mathrm{~km}$ al norte, para llevar a su ganado (Risopatrón 1910: 160). Actualmente la finca de San Bartolo, situada aguas abajo del sector minero, es reclamada por los Ayavire, pero está en manos de una familia procedente de Lampa (Santiago).

A continuación describiremos los diferentes elementos que forman este paisaje a partir de nuestras observaciones de terreno, los antecedentes recuperados de entrevistas etnográficas y la bibliografía y cartografía revisada.

\section{Los testimonios}

En el valle de San Bartolo hay una cantidad de sitios arqueológicos, prehispánicos e históricos que dan testimonio de una larga ocupación humana de este lugar, con asentamientos que esencialmente tuvieron la finalidad de explotar sus ricas minas de cobre nativo. La gran mayoría de estos sitios, en consecuencia, revisten la calidad de enclaves mineros.

Una completa descripción de este lugary la caracterización de sus sitios fue tema de otra publicación (Aldunate et al. 2005:213-225), lo que permite omitir en esta oportunidad sus detalles. Ahora sólo se ofrecerán datos y evidencias recuperadas con posterioridad y que no fueron publicadas anteriormente. Básicamente, un sendero peatonal que comunica la localidad de Río Grande con el valle de San Bartolo, y llega precisamente al sector de mayor concentración de restos prehispánicos que hoy recibe el nombre de "El Establecimiento" (Figura 3), donde se distingue un gran bloque con petroglifos rodeado de evidencias de fundición de metales. A pocos metros hay un cementerio prehispánico vinculado a una ocupación inca, dos collcas que aún conservan acumulaciones de cobre nativo, al menos un recinto de características prehispánicas tardías y dos plataformas. Algunos cientos de metros aguas abajo, en una quebrada denominada

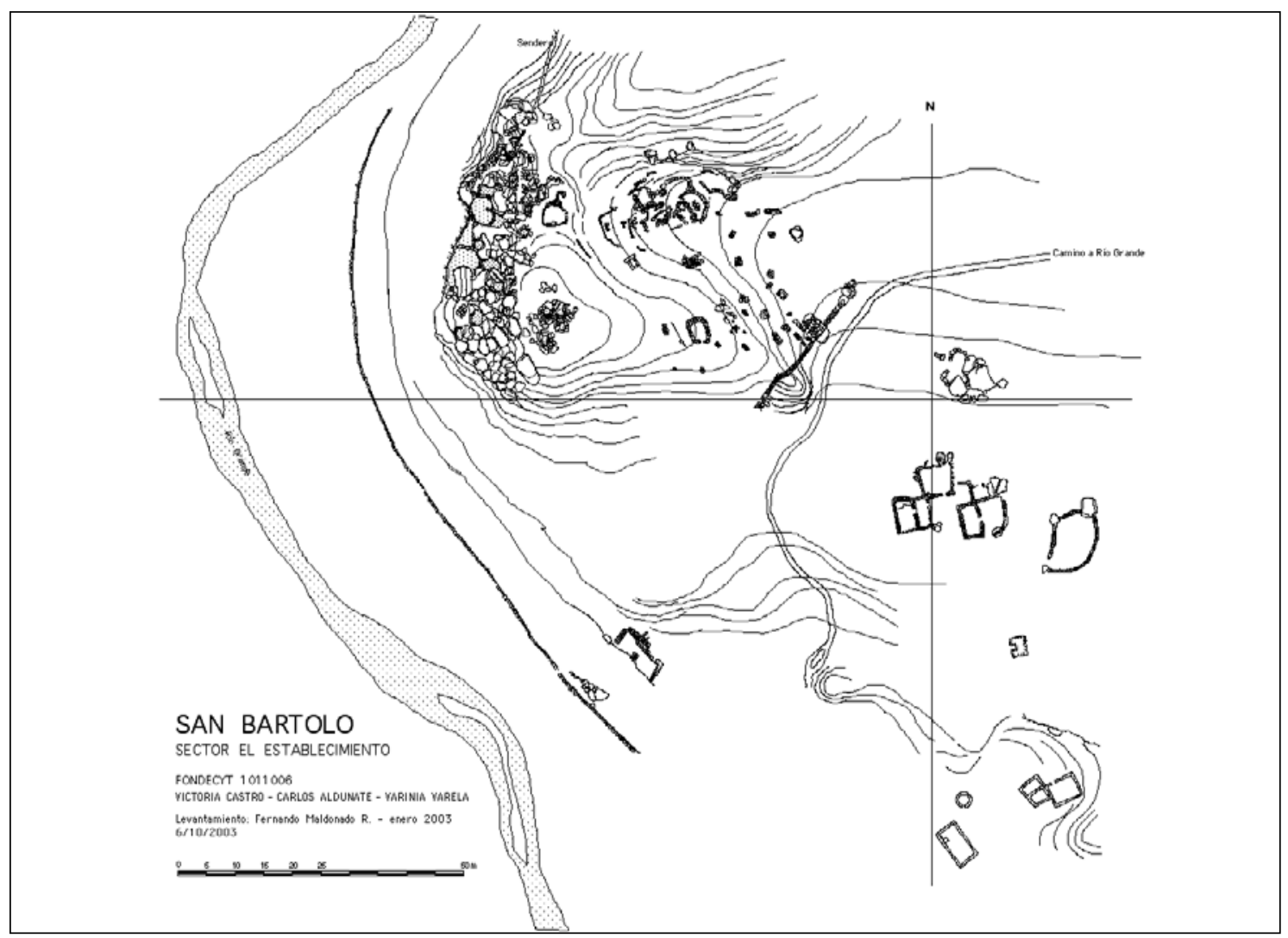

Figura 3. Levantamiento del sector “El Establecimiento” en San Bartolo. 
Palicaye, se encuentran las minas de cobre, explotadas desde épocas prehispánicas hasta el siglo XX.

Los sitios históricos representan las sucesivas faenas mineras que, a partir de mediados del siglo XIX, explotaron las ricas menas de San Bartolo. A cada una de estas ocupaciones se les ha dado el nombre del dueño del mineral.Así, se logró distinguir:a) Las faenas de don Diego de Almeyda establecidas allí cerca de 1840; b) las explotaciones de la casa Artola, de la segunda mitad del siglo XIX, cuyo centro de operaciones estaba en Cobija; c) El asentamiento de los hermanos Walker, de fines de ese mismo siglo, y d) La Planta de inicios del siglo XX con su cementerio, que se encuentra en el sector prehispánico "El Establecimiento".

Arqueologíay cronología. La cerámica prehispánica se encontró exclusivamente en el sector "El Establecimiento". En la muestra de superficie, el tipo de mayor popularidad es Turi Rojo Alisado o Grupo 1 (Varela et al. 1993). Dentro del cementerio histórico y vecino a la piedra de petroglifos, así como en el cementerio prehispánico, se encontraron concentraciones de cerámica asignada al Período Tardío, como el tipo Turi Rojo Revestido, los grupos inca locales (51 y 36) y Yavi, tipo proveniente del sitio homónimo del norte de Argentina y que caracteriza la ocupación inca en Atacama. Sometido a análisis de termoluminiscencia, un fragmento Yavi fue fechado en 1580 DC (UCTL 1653).

Se practicó un pozo de sondeo donde se ubicaron tres momentos de ocupación: la capa inferior acerámica con desechos de tallas y huesos muy astillados; una capa media que se asignó a un momento temprano del Intermedio Tardío por la abundancia de cerámica Dupont, y que fue fechada por TL en 1230 DC (UCTL 1645). De este nivel se extrajo un trozo de barrilla, o mineral nativo de cobre. La capa superior que incluye cerámica Ayquina y Turi Gris Alisado corresponde a un momento más tardío. En este estrato y en el superficial se encontraron escasos fragmentos de cerámica etnográfica colonial, que ha sido fechada en el siglo XVII (Varela 1992). ${ }^{11}$

\footnotetext{
${ }^{11}$ Definimos como "cerámica etnográfica colonial" a aquella realizada con tecnología indígena local en los siglos XVII y XVIII. Este tipo ha sido fechado por TL en el siglo XVII sobre muestras provenientes del Pucara de Turi, Chita, Vega Salada y El Peuco 5, y por C ${ }^{14}$ en Cobija 1
}

Un trozo de guaira recuperado en el sector del cementerio histórico fue fechado por TL en 1730 DC (UCTL 1824).

Mineralogía y metalurgia. El análisis de materiales producto de la explotación minera de San Bartolo hecho en los laboratorios del MIT (Alunni 2006) confirma que el mineral explotado en San Bartolo era cobre nativo con óxidos, cloruros y sulfuros de cobre, sin trazas de otros metales. Las dos muestras de barrilla (MIT 5313 y 5319) dieron una pureza de $58.2 \%$ y $85 \%$, respectivamente, de cobre puro.

El análisis de las escorias (MIT 5318 y 5316) demuestra que se agregó a la carga de fundición dióxido de manganeso $\left(\mathrm{MnO}_{2}\right)$ para acelerar la combustión y obtener un resultado más fluido para llegar a la temperatura de fundición del cobre $\left(1183^{\circ}\right)$. En la última muestra de escoria (MIT 5316), este agregado alcanza una concentración de $31.2 \%$, logrando un resultado muy exitoso, pues la escoria cristalizada arroja una muy baja proporción de cobre. Al contrario, en la primera muestra (MIT 5318) la proporción de $\mathrm{MnO}_{2}$ es más baja (4.1\%), lo cual no permitió una buena fundición, quedando una alta concentración de cobre en la escoria analizada. ${ }^{12}$

Los análisis del trozo de roca que sirvió como guaira (MIT 5320) muestran que la pared de este horno estuvo en contacto con una escoria fundida a alta temperatura, que contenía cobre nativo y sulfuro de cobre. La pared de horno se fundió en una profundidad de $2 \mathrm{~mm}$, permitiendo al mineral nativo pasar a través de la escoria y del horno. La temperatura debió alcanzar más de $1125^{\circ}$ para fundir la roca (Alunni 2006). En resumen, los análisis demuestran que en San Bartolo, durante el siglo XVIII se utilizaba un sistema metalúrgico de clara raigambre prehispánica, demostrada por el uso de guairas para fundir minerales complejos que contenían cobre nativo, sulfuros y óxidos. Sin embargo, el análisis de las escorias

Norte. Incluye los tipos $\mathrm{P} / \mathrm{m}$ (pasta con mica) (Varela et al. 1993) y Turi Café Alisado (Uribe 2002).

${ }^{12}$ El uso de este elemento como un efectivo fundente se constata en Israel en la Edad del Bronce Tardía y en la Edad del Hierro Temprana (Alunni 2006). 
sugiere que la proporción de sulfuros fue más baja que la de óxidos. Este sistema de fundidos combinados y el uso de manganeso como activo fundente no hizo necesario contar con condiciones reductoras vigorosas para producir un alto grado de separación entre el cobre y la escoria (Alunni 2006).

Toponimia. Los topónimos y sus ubicaciones, contenidos en el mapa de la Comisión Chilena de Límites (1907) hecho sobre la base de las informaciones cartográficas de Risopatrón (1910) y Golborne (1906, cit. en Risopatrón 1918), nos han ayudado a aclarar las distintas etapas de las faenas mineras republicanas en San Bartolo.

Compañía Artola Hnos. En las cabeceras de la quebrada de Palicaye se encontraba la mina manifestada en 1848 por don Diego de Almeyda y que explotaba la firma Almeyda, Elizalde y Puch (Philippi 1860: 62). La descripción de las elementales instalaciones descritas para esa ocupación no se compadece con los restos allí situados, que evidencian algo mucho más complejo, que posiblemente corresponda a la explotación efectuada por los Artola.

El topónimo Artola del mapa de 1907 coincide con el de la actual carta IGM 1:50.000 de Río Grande y sugiere que después de Almeyda se estableció en un sector aguas abajo, que hoy llaman La Planta de San Bartolo, un campamento de la famosa firma Artola Hnos., formada por españoles que se dedicaban a la extracción, compra y transporte de minerales y que establecieron fundiciones en Bolivia y Chile (ver Figura 2). Llegaron a Cobija alrededor de 1840, donde primero se establecieron como agentes de transporte de carga desde ese puerto al interior de Bolivia (Risopatrón 1910: 148). El 6 de abril de 1848 consiguieron una concesión del Gobierno de Bolivia para el establecimiento de máquinas de trituración y depuración de minerales de cobre. De acuerdo a los términos de esta concesión, ella se limita exclusivamente al puerto de Cobija y a los minerales de San Bartolo, los que comienzan a explotar en 1864. Los Artola habían establecido fundiciones en Gatico, cerca de Cobija (Herrman 1900: 163), y en 1862 habrían construido el faro de Cobija (Arce 1997: 26, 68).
Según una fuente (Armas s/f), el apogeo de la mina San Bartolo fue en esta época (hacia 1856), con una población de 3000 habitantes ${ }^{13}$, cantidad que parece exagerada. ${ }^{14}$ Este auge no habría durado mucho, pues cuando Bertrand (1885:23) viaja a las cordilleras de Atacama, señala que al llegar a San Bartolo pasó sin detenerse por "el establecimiento abandonado de los señores Artola" y que no pudo entrar a las labores "que estaban casi todas ellas aterradas o anegadas".

La compañía Artola Hnos. se involucró en la explotación de los recursos salinos del salar de Ascotán con malos resultados (Valdés 1886:162) y se disolvió a fines de 1869 (Bermúdez 1966: 77). Sin embargo, en 1875 aún figuraba con unas pocas acciones dentro de los accionistas de la mina Huanchaca. La familia Artola siguió hasta principios del siglo XX dedicada a negocios mineros en Bolivia (Arce 2003: 145).

En la quebrada de San Bartolo, la casa Artola explotaba las siguientes minas: San Bartolo, 15 de febrero, Indiana, Aurora I, Aurora II, San José, Otoño, Invierno, Primavera y Verano (Risopatrón 1910: 148).

De acuerdo a informaciones de riograndinos, el libro de la iglesia de Río Grande, perdido desde 1973, consignaba el encargo que se hizo a Artola para obtener una campana para esta iglesia, que debería llegar desde España.

En su viaje de 1880, Bertrand (1885:22) constata que en San Bartolo existe un "establecimiento abandonado de los señores Artola, en las minas de barrilla de cobre. Más tarde, Risopatrón (1924:50) menciona para el valle de San Bartolo el topónimo Finca de Artola, un sector de "70 hectáreas de alfalfares, higueras, vides, etc. Se consiguen en ella corderos y pasto cortado..." Posteriormente, (1910: 148) este autor señala que a inicios del siglo XX

13 Correspondería a la época de Artola nuestro hallazgo de una moneda: "un cobre" chileno de 0.5 centavos, fechado en 1852 . Según informaciones numismáticas, se acuñaron en Inglaterra y Estados Unidos entre 1851 y 1853 .

14 Vidal Gormaz (1879: 14) señala que en San Bartolo existían "magníficos edificios" en "El Establecimiento", cuyo costo avalúa en unos 400.000 pesos. Agrega que "se ocupan en sus labores más de 200 peones, la mayor parte chilenos". 
la sucesión Artola compartía con los hermanos Walker explotaciones en San Bartolo. Aguas abajo de la Finca de Artola se encontraban los Potreros de Ayavire, topónimo relacionado con la familia originaria de este lugar y que probablemente también destinaba los productos de sus cosechas al laboreo de la mina.

Walker-Bokar. Compañía Walker Hnos. Risopatrón (1910: 148) señala que en los inicios del siglo XX "el mineral de San Bartolo se divide en dos grupos, pertenecientes uno a la sucesión del señor Norman Walker i el otro lo fue a la casa Artola". Los Walker explotaban las minas llamadas Londres y Palicaye. En esta ocasión constata que ambos mineros habían construido establecimientos de lavado de barrillas.

Las construcciones de Walker delatan una actividad relevante hecha por una compañía minera formada por los hermanos Walker, descendientes de Norman Walker, un inglés llegado a Copiapó a mediados del siglo XIX.A fines de ese siglo, eran dueños de pertenencias mineras en Chuquicamata, junto con los hermanos Hoffmann. ${ }^{15}$ También beneficiaron la mina del Salado, descubierta por don Diego de Almeyda en Chañaral, antes que pasara a propiedad de la casa Edwards. Uno de ellos, don Tomás Walker, trabajó la famosa mina del Morado, cerca de Vallenar (Vicuña Mackenna 1883:212 y 230). En el sector Bokar (Walker) de San Bartolo se registró un petroglifo en las instalaciones mineras con la fecha "julio de 1898", que establece un hito cronológico congruente con la ocupación por los Walker durante esa época.

\section{* Cobija}

Cobija, punto central del área prospectada en esta investigación, se sitúa a los $22^{\circ} 33^{\prime}$ Lat. Sur y $70^{\circ} 16^{\prime}$ Long. Oeste, en un estrecho plano del borde de la rada. Por el este la circundan los cerros de la Cordillera de la Costa que alcanzan más de $900 \mathrm{~m}$ de altitud, y por el oeste la

\footnotetext{
15 Norman Walker, asociado a Samuel y Rodolfo Hoffmann encontraron en sus pertenencias de Chuquicamata al famoso Hombre de Cobre (Bird 1979), momia cuprificada de un minero del siglo VI DC (Adriana Hoffmann, com. pers. 2005).
}

baña el océano Pacífico. Como puerto es relativamente abrigado de los vientos del sur, pero no presenta facilidades para el desembarque de grandes navíos. Sin embargo, sus mayores inconvenientes siempre estuvieron ligados a la escasez de agua (las poquísimas aguadas son de mala calidad), la ausencia de vegetación y pastos para talaje. Adicionalmente, la dificultad de acceso desde Cobija al interior - hay que atravesar casi $100 \mathrm{~km}$ de desierto absoluto para acceder a los oasis de Atacama- está señalada en la literatura como un inconveniente casi insalvable para establecer allí un puerto. ${ }^{16}$

A pesar de estas limitaciones, desde épocas prehispánicas Cobija despertó el interés de los pueblos de Atacama y del Loa, quienes accedieron a los ricos recursos marinos que allí se ofrecían. Durante la administración colonial, el "Puerto de la Madalena de Cubija" es residencia de españoles e indios vinculados a la pesca, recolección marina y al tráfico de Potosí. En la naciente República de Bolivia, el Gobierno hace ingentes esfuerzos por habilitar caminos, postas y arrierías para continuar este vínculo. A pesar de que nunca pudo lograr a cabalidad este propósito, bajo la administración boliviana Cobija se transforma en un puerto con más de mil habitantes (Fifer 1975), que cumple con la significativa función de vincular las tierras del interior con el Pacífico, desde donde llega todo el abastecimiento de ultramar, tan importante para la economía del siglo XIX. Además, en sus inmediaciones hay importantes actividades mineras de plata y cobre, y en la pampa contigua se inician las explotaciones salitreras.

Cobija dejó de ser importante como puerto en la década de 1870, después de dos intensos terremotos que resultaron en sendos maremotos y un gigantesco aluvión que destruyeron las edificaciones e instalaciones portuarias. Para finalizar la desastrosa década, la Guerra del Pacífico, que anexó estos territorios a Chile y el ulterior desarrollo de los exitosos puertos de Mejillones y de Antofagasta, terminó esta labor, dejando a Cobija sumida en el más completo abandono, sin que nunca más se oyera hablar de su antigua población originaria (Risopatrón 1924:222).

\footnotetext{
${ }^{16}$ Ver Frezier (1716: 130) y Cañete y Domínguez (1952 [1787]: 269 y siguienres), entre otros. 


\section{Antecedentes arqueológicos}

La investigación arqueológica en Cobija ha centrado su interés en estudiar la ocupación humana durante el Período Arcaico. Aparte de las investigaciones prospectivas de Schaedel (1957), Berdichewsky (1965) y Cruz y Bravo (1980), son especialmente significativos los trabajos de Llagostera (1979, 1989, 2005) en la costa de Antofagasta y de Agua Dulce, al sur de Tocopilla, que le han permitido al autor plantear un modelo teórico en relación al proceso de adaptación y desarrollo de las sociedades pescadoras y recolectoras costeras en estos espacios durante el Período Arcaico.

Respecto a los períodos agroalfareros, Latcham (1927) describe algunas piezas cerámicas procedentes de la zona de Cobija y señala que son de origen atacameño. También reconoce una cerámica miniatura señalando que la excavó en Cobija, en "sepulturas de adultos" en las localidades de El Cobre, en Cobija y en Caldera (1928: 92). Señala también haber visto ejemplares de alfarería negra propia de San Pedro de Atacama, en El Cobre, Paposo, Cobija, Antofagasta y otras regiones de la costa.

Moragas (1982) hace investigaciones en el sitio Cobija 10 , definiendo un cementerio de alrededor de 90 túmulos, con fechas de 320 y 350 DC que adscribe a una influencia de "Alto Ramírez", con adaptaciones locales, especialmente determinadas por las condicionantes desérticas del lugar sin cursos de agua, lo que imposibilita la agricultura.

Berdichewsky (1965), a raíz de su prospección, propone una tipología cerámica para la localidad de Copaca, en el área de Cobija. Por su parte, Larraín (1966) hace una contribución al estudio de una tipología cerámica de la zona de Antofagasta, con una muestra procedente de numerosos sitios arqueológicos entre la península de Mejillones y Trocaderos y pesquisa la presencia de cerámica de San Pedro de Atacama en puntuales conchales de la zona.

Sin embargo, es Latcham quien primero sugiere explotaciones mineras prehispánicas en el sector de Cobija. Señala que "en Chile, los objetos de metal se han encontrado en mayor abundancia en la región de la costa, especialmente en Tongoy, La Serena, Caldera, Taltal, Paposo, Antofagasta y Cobija" (1936: 109), agregando que hizo analizar algunos objetos de cobre de estas localidades y que todos contienen estaño, salvo unos pocos, en que el cobre se presenta con más pureza (1936:111). Indica también que en los sitios de la costa, entre los que menciona Cobija, eran muy comunes los anzuelos de cobre o de bronce durante la época "Chincha Atacameña" (1936:136).

Aunque Bittman (1979, 1983, 1884a, 1984b, 1984c) no consideró la minería como una actividad específica de estudio en Cobija, menciona sitios de actividades mineras, tanto de cateo, extracción de minerales como de fundición y habitaciones de mineros, todos de tiempos históricos.

Desde una perspectiva interpretativa, Latcham (1928) señala que durante los primeros siglos de la era cristiana "parecen haber llegado a la costa ciertas influencias atacameñas, las que posteriormente se hicieron sentir de una manera más profunda en todo el litoral, hasta Caldera por el sur". Menciona que a fines del Período Tiwanaku "los atacameños parecen haberse extendido hasta la costa, mezclándose con las tribus pescadoras y aportando a esa región algunos elementos especiales de su cultura..." (Latcham 1928:43). Por otra parte, Núñez y Dillehay (1979) proporcionan datos arqueológicos suficientes para confirmar la presencia cultural de las tierras altas en el desierto costero desde épocas formativas hasta la incaica.

En esta investigación se han podido confirmar y documentar las hipótesis precedentes para el sector de Cobija, acreditando la presencia cultural de San Pedro de Atacama y de los oasis del río Loa, incluyendo Quillagua, en el registro arqueológico del sector prospectado entre Punta Tames y Punta Atala.

\section{Antecedentes históricos}

Durante el Período Colonial es abundante la información sobre Cobija que se refiere a su especial característica de ser el centro de vinculación de las tierras altas de Charcas con la costa, tanto así que el "Camino de Potosí” llegaba 
precisamente a este puerto. Sin embargo, no hay noticias acerca de explotaciones mineras en este litoral.

En la época republicana temprana, el Mariscal Santa Cruz trató de incentivar la minería en la zona de Cobija para atraer a inmigrantes. Para ello adoptó el sistema liberal de concesionar las minas a particulares y permitir la libre exportación de cobre. Surgieron así las plazas extractivas de cobre en Gatico, Copaca, Tres Cerros y Mamiña. ${ }^{17} \mathrm{~A}$ fines de 1830, los comerciantes de Cobija se interesaban en la explotación de minas de cobre cateadas frente al puerto, a una distancia de 1.2 y 3 millas de la misma playa del embarcadero. Las primeras noticias de explotaciones mineras en Cobija las entrega d'Orbigny (2002: 1032, 1035),y se refieren a una mina de cobre y una de planta en explotación en 1830, pero, al parecer, eran muy rudimentarias. Los empresarios interesados exigían garantías al gobierno para solucionar los innumerables obstáculos que se presentaban, que sobre todo eran de carácter financiero y de infraestructura, escasez de agua para las faenas y de combustibles para la fundición. ${ }^{18}$

En 1832 el gobierno da la concesión de los minerales de Gatico - considerados los más ricos de esta región- a una sociedad compuesta por don Dámaso Uriburu, con sede en Valparaíso, Gregorio Beeche, sede Potosí, y un señor Zamudio, de nombre no explicitado, de Cobija.El Mariscal Santa Cruz, al parecer, formaba parte de esta sociedad y se ocultaba bajo el nombre de su sobrino, José Peña (Cajías 1975: 343). Estas minas, junto a las de Copaca, Tres Cerros y Mamiña, fueron abandonadas después de la invasión peruana a Cobija, comandada por Salaverry en 1835. Años más tarde su explotación parece restablecida, pues en 1840 se exportan 8488 qq de cobre de Cobija (1977:345). Con posterioridad, las minas de Gatico aparecen en manos de la firma Artola Hnos.(Herrman 1900:163), los mismos que explotaban San Bartolo.

\footnotetext{
17 Un informe dice que estos minerales de Cobija tenían una ley de 25\%, que en ocasiones llegaba a 60\% (Cajías 1975:344).

${ }_{18}$ Un proyecto planteaba la posibilidad de llevar los minerales por mar a la isla de Juan Fernández, donde se podría establecer una fundición (Cajías 1975:341).
}

A mediados del siglo XIX, el viajero francés León Palliere (1945: 175) desembarca en Cobija rumbo a Saltay describe que en este puerto había una máquina a vapor para triturar metales, evitando el alto costo de importar carbón. Esta máquina estaba alimentada por agua de mar y se usaba, al mismo tiempo, para desalinizar este vital elemento y abastecer de agua dulce a Cobija. ${ }^{19}$ Señala, además, que casi todas las minas de Cobija eran explotadas por franceses y que había muchos pequeños yacimientos de cobre en las laderas de los cerros, trabajados por pirquineros (1945: 177).

En 1870, José Díaz Gana, gran cateador de minerales nacido en Valparaíso, alertado por un hallazgo de un rodado de plata de alto contenido metalífero, de acuerdo a ensayos practicados en Cobija, se asoció con el francés Arnous de la Riviere, explotador de guaneras en Mejillones, y con otro cateador, el chileno José Ramón Méndez, para organizar una expedición de búsqueda del mineral de plata encontrado en las serranías del cerro Limón Verde, algunas decenas de kilómetros al sur de Calama. Lo llamaron Caracoles por la cantidad de fósiles marinos que formaban los depósitos geológicos del sector (Bravo 2000).

El mineral se encontraba separado del litoral por cinco jornadas penosas de camino de carretas, con carencia absoluta de agua, lo que constituyó uno de los principales obstáculos que hubo que solucionar. ${ }^{20} \mathrm{Como}$ durante los primeros tiempos de Caracoles el mineral se embarcaba en Cobija, se tuvo que construir un camino que subía por Gatico, los cerros de Colupo, donde había una precaria posada, y luego se cruzaban 19 leguas hasta las riberas del Miscanti, donde había otra posta miserable y un poco de agua de mala calidad. De Miscanti se partía a Guacate y de allí a Calama, el principal oasis del río Loa, desde donde se accedía a Caracoles cruzando a veces pantanos

19 El agua dulce se vendía a 3 reales el barril de 80 botellas (un peso tenía 8 reales y equivalía a 5.25 francos) (Cajías 1975:341).

20 Cajías (1975:380-386) publica un interesante diario de viaje de La Paz a Cobija en 1830, donde se aprecia a cabalidad la rigurosidad del camino. Señala que en el último tramo, al llegar a Cobija "todo este camino se ve sembrado de esqueletos de burros y mulas que la sed, el hambre y el cansancio hacen espirar". 
producidos por las frecuentes crecidas de este río (Bravo 2000: 44-45).

Gracias a Caracoles, la población de Cobija, que en 1850 era de unas 2000 almas (Cajías 1975: 65), comenzó a crecer y llegó a tener más de 3000 habitantes en 1871, a pesar de las dificultades en abastecimiento de agua, que siempre era crítica, no obstante las máquinas de destilación que se instalaron en este puerto, así como en Antofagasta. El problema del agua afectaba también las labores de Caracoles que se tenía que surtir de este vital elemento desde Calama o Chiu Chiu a precios elevadísimos (Bravo 2000:45). Las mismas dificultades de abastecimiento, de recursos y otras que afectaron a Cobija, también son aplicables a la explotación de Caracoles, a pesar de lo cual seguía llegando mucha gente atraída por la fiebre de la plata.

Este crecimiento de Cobija fue efímero, pues, también gracias a Caracoles, los puertos de Mejillones y Antofagasta comenzaron a desarrollarse a raíz de las mejores condiciones de fondeamiento y portuarias, así como por el nacimiento de la industria salitrera. Ellos terminaron por desplazar por completo a Cobija, a pesar de los intentos del gobierno boliviano que trataba vanamente de impedir la "desbolivianización" de Caracoles, y aunque casas comerciales bolivianas tan importantes como Artola Hnos. iniciaran la construcción de caminos carreteros entre Cobija a Caracoles. Tampoco resultó el proyecto de construir un ferrocarril entre Cobija y Caracoles, cuya concesión fue entregada por el gobierno boliviano favoreciendo a Mejillones (Bravo 2000: 56).

\section{Los testimonios}

Arqueología y cronología. En el sector de prospección arqueológica, entre Punta Atala y Punta Tames, se han detectado una decena de sitios con vocación minera (Figura 4). ${ }^{21}$ Entre ellos, la mayoría corresponden a explotaciones medianas o pequeñas correspondientes al siglo XX. Hay dos establecimientos que sugieren haber estado en uso

\footnotetext{
${ }^{21}$ Nuestro proyecto los ha identificado como: Copaca 5, Mantos de la Luna 1, Mantos de la Luna 3, Guanillos 2, Gatico, Mantos del Pacífico 1, Mantos del Pacífico 8, Guasilla 27 y Guasilla 28.
}

desde la primera mitad del siglo XIX. Uno de ellos es Gatico (UTM 372753 E / 7511586 N), impresionante y compleja instalación minera, actualmente abandonada, que también conocemos por la literatura histórica de la zona y que fue explotada desde 1840 hasta entrado el siglo XX. El otro es Guanillos 2 (UTM 370970 E / $7521543 \mathrm{~N}$ ), que en la literatura aparece como puerto boliviano, aguada y establecimiento minero. Las ruinas de este complejo sitio demuestran que se trata de una sola ocupación de inicios del siglo XIX, hoy abandonada y que allí se cumplían todas las etapas del proceso industrial metalúrgico, desde la extracción hasta la fundición, e incluso el traslado del mineral, como lo demuestran los restos de hornos y el muelle en ruinas. Hay también sitios habitacionales asociados a esta industria.

El sitio Guasilla 27 (UTM 370188 E / 7501868 N) representa una ocupación minera del Período Colonial Temprano y/o posiblemente prehispánico, con piques mineros con evidencias de extracción de minerales, guairas y círculos de piedras que pudieran ser prehispánicos. De este sitio se extrajeron muestras de escorias y guairas para su análisis y fechamiento por termoluminiscencia. Este último procedimiento arrojó una fecha de $3970 \mathrm{AC}$ (UCTL 1823), que parece defectuosa, ya sea por defecto del análisis o de la muestra.

Mineralogía. Domeyko señala que en la mina La Libertad de Cobija hay "cobre negro" o "polvorilla de cobre", un mineral de alta ley ${ }^{22}$, que los mineros denominan "negrillo" (1897:201). También hay atacamita u oxicloruro de cobre ${ }^{23}$, cobre sulfúreo, chalcocita, covelina o bronce añilado y minerales de cobre clorosulfurados, algunos de gran pureza (1897: 209, 215, 216).

Estudios geológicos actuales acerca del origen y composición mineralógica de la Cordillera de la Costa de Antofagasta señalan que las rocas volcánicas basálticoandesíticas de la Formación La Negra y las rocas plutónicas de composición gábrica a granítica, que las intruyen, hospedan depósitos de cobre con contenidos variables

\footnotetext{
2279.83 de cobre y 21.17 de oxígeno.

23 Compuesto de cloro (15\%), cobre metálico (13\%), deutóxido de cobre $(54 \%)$ y agua $(20 \%)$.
} 


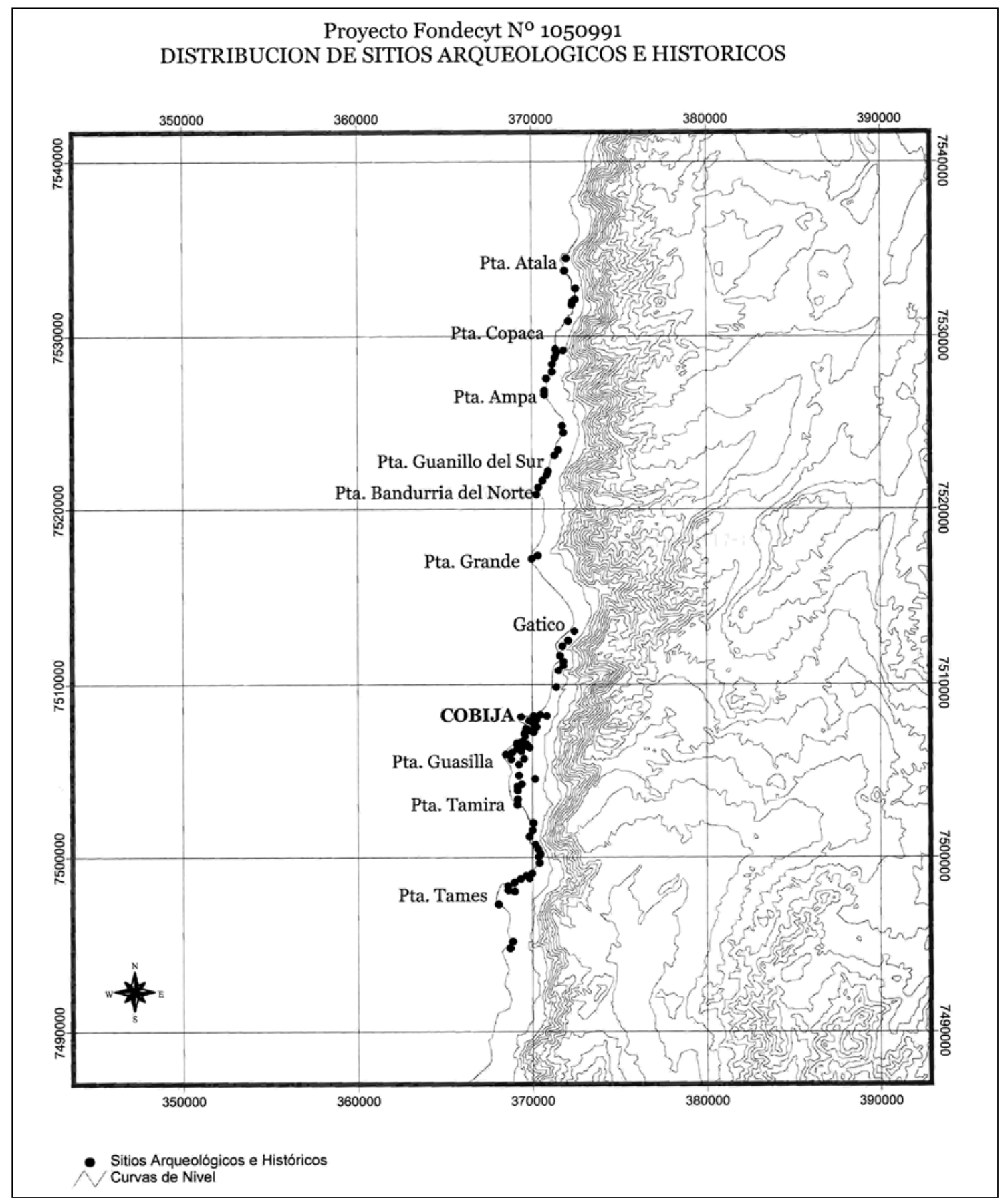

Figura 4. Prospección del litoral entre Punta Tames y Punta Atala, Cobija.

de plata, oro y hierro. Los yacimientos estratoligados de cobre-plata, que incluyen tanto depósitos estratiformes como chimeneas de brechas, se hospedan preferentemente en la secuencia volcánica, mientras que los yacimientos vetiformes de cobre-hierro y oro (calcopirita-magnetita- actinolita) se restringen a los cuerpos intrusivos. Las relaciones espaciales y temporales entre ambos tipos de depósitos sugieren un origen hidrotermal común, del Jurásico Medio a Superior. Los yacimientos vetiformes fueron formados en la zona plutónica, de más 
alta temperatura, a partir de soluciones magmáticas en equilibrio con magnetita y condiciones de $\mathrm{pH}$ neutro a ligeramente alcalino, como lo indica la presencia de magnetita asociada a los minerales de mena y albita o feldespato potásico entre los minerales de alteración. Estas soluciones migraron hacia zonas más superficiales y condiciones más oxidantes, con hematita estable y menor temperatura, para dar origen a los depósitos estratoligados alojados en las rocas volcánicas (Vivallo y Henríquez 1998).

\section{* Minería y metalurgia en San Bartolo}

La actividad minera prehispánica en Atacama está documentada desde el Formativo Temprano en las comunidades pastoras de Tilocalar, entre 1200 y 500 AC (Núñez 1999: 179). En el Formativo Tardío (ca. $50 \mathrm{AC}$ ) se ha registrado en el sitio de Ramaditas en Guatacondo, región de Tarapacá (Graffam et al.1995-1996). Durante el Período Medio se encuentra presente en las fases Quitor, Sequitor y Solor de San Pedro de Atacama (Núñez 1999) y experimenta un auge durante la expansión Tiwanaku, período en que se explotaron yacimientos de cobre en Chuquicamata (Bird 1979). En el Período Intermedio Tardío, los contextos señalan una disminución de artefactos de cobre, que Núñez explica por la concentración de poder en manos de las élites que monopolizan estos elementos de prestigio y la eventual exportación de metal y mineral (1999: 180). Durante el Tawantinsuyu, a la economía estatal le interesaba aumentar la producción de este metal y reorientó la ocupación de los espacios y el trabajo de las poblaciones locales de Atacama hacia este interés central, subordinando los intereses de las comunidades atacameñas a este objetivo. Son conocidos los establecimientos mineros incas de Yabricollita o Collahuasi, El Abra (Núñez 1999; Salazar 2002), Incahuasi y Cerro Verde en Caspana (Castro 1992; Adán 1999). San Bartolo constituiría otra clara situación en este mismo sentido. Hasta ahora no hay evidencias claras de explotaciones mineras prehistóricas en el litoral de Atacama, fuera de la probable filiación prehispánica del sitio de Guasilla 27.

Los datos que hemos recuperado evidencian una ocupación de San Bartolo desde el Período Intermedio
Tardío, que perdura hasta la ocupación inca. Aunque es probable la existencia de una industria minera anterior, atestiguada por el hallazgo de mineral nativo en los estratos correspondientes al Intermedio Tardío, es durante el Período Tardío o Inca cuando hay más evidencias de explotación de minerales de cobre en Palicaye, así como probables labores de fundición y almacenamiento de la producción metalífera en collcas. A esta época pertenece el cementerio de cámaras subterráneas en la ladera rocosa, donde se enterró a los muertos y muy probablemente también se efectuaron prácticas ceremoniales junto a la piedra de petroglifos y en dos plataformas en forma de "U" abiertas hacia los $250^{\circ}$ suroeste.

Los testimonios arquitectónicos, el cementerio, arte rupestre y restos muebles avalan este aserto. El estudio de la cerámica también ha comprobado una ocupación del valle desde el Período Intermedio Tardío (ca.120o DC) $y$ actividades mineras que probablemente se intensifican en épocas incaicas.

Hasta ahora no hemos encontrado restos de artefactos de metal que puedan dar indicios de los procesos de elaboración de los mismos aunque, a juzgar por los testimonios de fundición, es posible que esta industria se desarrollara en la localidad. Hay que considerar, sin embargo, que Latcham (1936) y Philippi (1860) mencionan el hallazgo de artefactos de metal ${ }^{24}$ junto con restos de escorias, que señalan "la probable existencia de huayras u hornillos de fundición. Es posible que estos fragmentos sean instrumentos malogrados en la fundición" (Latcham 1936: 105).

Las evidencias encontradas en San Bartolo se compadecen con las estudiadas en los vecinos enclaves mineros prehispánicos de San José del Abra y Conchi por Núñez (1999) y Salazar (2002). Este último autor también encuentra pequeños laboreos estacionales del Intermedio Tardío, seguidos por una explotación más intensiva en el Tawantinsuyu, época en que mineros locales trabajaban

24 "Dos fragmentos de puntas de hachas resguardadas en el Museo Nacional de Chile, una con filo semilunar, ambos con hendiduras longitudinales de $3 \mathrm{~mm}$ de ancho y $1.5 \mathrm{~mm}$ de profundidad" (Latcham 1936: 107). 
para el Inka, probablemente como mitayos. En San Bartolo no hemos encontrado los campamentos habitacionales del Tardío, los que probablemente han sido borrados por aluviones o por las sucesivas ocupaciones históricas del asentamiento. Es difícil especular acerca de la cantidad de personas que trabajaban en las actividades mineras, pero la cerámica encontrada atestigua la presencia de población local. La cerámica Yavi, aunque es de filiación chicha, es un marcador temporal y cultural de la presencia inca en Atacama.

Después de la conquista y durante la colonia fueron el oro, la plata y el azogue los protagonistas de las actividades mineras en los Andes, quedando el cobre reducido a algunos escasos laboreos, que tuvieron un pequeño repunte el siglo XVIII (Vicuña Mackenna 1883). En Conchi Viejo y San José del Abra durante ese siglo los mineros de origen local han abandonado estas labores por las tradicionales de pastoreo y agricultura (Salazar et al. 2004). Los documentos históricos dan testimonio de la presencia de población indígena de Tarapacá (Guatacondo y Pica) trabajando para los españoles dueños de las minas, probablemente como asalariados. También algunos de estos indígenas forasteros eran dueños de yacimientos en estas localidades. Estos tarapaqueños, al parecer, se mezclan con la población local, pues sus descendientes aparecen en el siglo XIX como dueños de tierras en Chiu Chiu y otras localidades vecinas. La explotación de estos yacimientos, que sigue siendo importante en el siglo XVIII, decrece durante el siguiente siglo XIX cuando se practican explotaciones de tipo individual (pirquineros) y de escasa intensidad, pues los mineros son a la vez pastores y agricultores.

En todo caso, la situación de San Bartolo es diametralmente opuesta a la de Conchi y El Abra, pues sus yacimientos, aunque se explotan durante la Colonia, sufren un intenso laboreo muy temprano en el siglo XIX, bajo el sistema de concesiones otorgadas a extranjeros.

Fue a mediados del siglo XIX cuando se produjo el gran auge de la minería del cobre, por los altos precios de este metal y las labores de pioneros mineros e industriales establecidos en Chile y Bolivia. Las tempranas instalaciones republicanas en San Bartolo registradas por Von Tschudi (Lehnert 1996) y Philippi (1860), así como la de la firma Artola Hnos., seguidas por los hermanos Walker, son representativas de este auge.

En el sector de Cobija ocurre un fenómeno análogo. Después de las concesiones tempranas del gobierno boliviano en 1830, el laboreo de minas y su procesamiento industrial se intensifica desde mediados del siglo XIX. Los restos arquitectónicos de esta época registran las mayores instalaciones, en las cuales vivieron cientos de operarios. ${ }^{25}$ Las obras hidráulicas de gran envergadura incluyen instalaciones para el lavado de la barrilla en San Bartolo, y terraplenes que aún conservan restos de líneas de los carros que trasladaban el mineral desde la quebrada de Palicaye a la Planta de Lavado de los hermanos Walker. Los tipos de loza del siglo XIX e inicios del XX son también abundantes, y entre ellos destaca la más temprana blanca con esmaltes azulinos, que también hemos encontrado en Cobija, Katisuna y en tambos incaicos. ${ }^{26}$ Para el litoral de Cobija, incluso se hicieron plantas desalinizadoras de agua para remediar su casi absoluta escasez.

\section{- Condiciones de trabajo}

A pesar de la profusión de minas y faenas mineras que se desarrollaban durante el siglo XIX y la cantidad de personas involucradas en el laboreo de las mismas, son muy escasos los datos acerca de las condiciones en que trabajaban los mineros. En general abundan datos geológicos, geográficos, empresariales, etc., pero las fuentes callan respecto de los actores principales de esta epopeya. En su famosa obra "El Cobre", Benjamín Vicuña Mackenna transcribe una excelente descripción de las faenas de cobre en el yacimiento del Salado, en

\footnotetext{
25 Los testimonios arquitectónicos están refrendados por informaciones de viajeros (Vidal Gormaz 1879: 13).

26 Entre los tipos de loza, el más temprano es el tipo i: loza blanca pintada a mano de azulino con bordes difusos, generalmente con motivos florales. Otros tipos son decorados por medio de impresiones o estampados con motivos florales, campestres, arquitectónicos y escenas de distintos colores (morado, verde azul, burdeo, negro sobre blanco) y son de probable origen belga, francés, checo u holandés, y de inicios del siglo XX. Se encuentra tanto en las tierras altas como en el litoral de Atacama. El tipo de loza más moderno (2) es de fabricación norteamericana (Varela et al. $2004 \mathrm{Ms}$ ).
} 
Chañaral, hecha en 1840 por un "escursionista minero" que entrega algunos datos sobre los trabajadores de la mina durante el siglo XIX. Pensamos que ellos se pueden extender a Atacama durante este período.

"Entre los operarios de las faenas se distinguen dos categorías: los pirquineros $i$ los operarios a jornal. Los primeros trabajan independientemente en una o más labores que el administrador o dueño de la mina le haya dado de antemano. Pueden tomar a sueldo los operarios que quieran, pero la mina responde por los sueldos de los últimos.

La mina está obligada a proporcionarles casa en que vivir, que estas son siempre mui miserables, hechas de pircas i esteras, i la aviación consiguiente de la tienda, compuesta de los materiales i herramientas para el trabajo i los viveres para la mantención. Los pirquineros a su vez están obligados a entregar los metales que exploten a la misma mina, a un precio fijado al comienzo del mes, que siempre es de veinte a cuarenta centavos ménos que el corriente de plaza; a pagar un tanto de arriendo o derechos, que siempre es de diez a treinta porciento del valor líquido de los metales deduciendo fletes; a pagar ensayes, extracción $i$ un tanto para el hospital de Chañaral en algunas, ifinalmente a cubrir la deuda de la tienda por las mercaderías suministradas en la temporada. Esta es jeneralmente de uno o dos meses de duración.

Los operarios a jornal, unos son barreteros o apires, llenadores, chancadores, carretilleros, etc. Todos están obligados a trabajar de seis a seis del día natural, tomando dos horas para almorzary comer" (Vicuña Mackenna 1883: 216 y siguientes).

El cronista da detalles sobre el trabajo que realizan y los sueldos que se pagan mensualmente a barreteros, apires ${ }^{27}$ (Figura 5) y llenadores y sobre la ración de comida que reciben ("una porción de frejoles o charqui guisados, un galón de agua i una telera de pan de una libra de peso"). ${ }^{28}$ Detalla las jornadas y turnos de trabajo y el faenamiento del mineral extraído: trituración manual por martillos, harneado para separar la colpa o metal grueso del llampo, metal molido, y granzas, metal un poco más entero, la

\footnotetext{
${ }^{27}$ Apiri (quechua): porteador, obrero que transporta mineral a la espalda (Diccionario Minero)

28 Telera: pan grandey de forma ovalada que suelen comer los trabajadores (Diccionario de la Real Academia Española 1972).
}

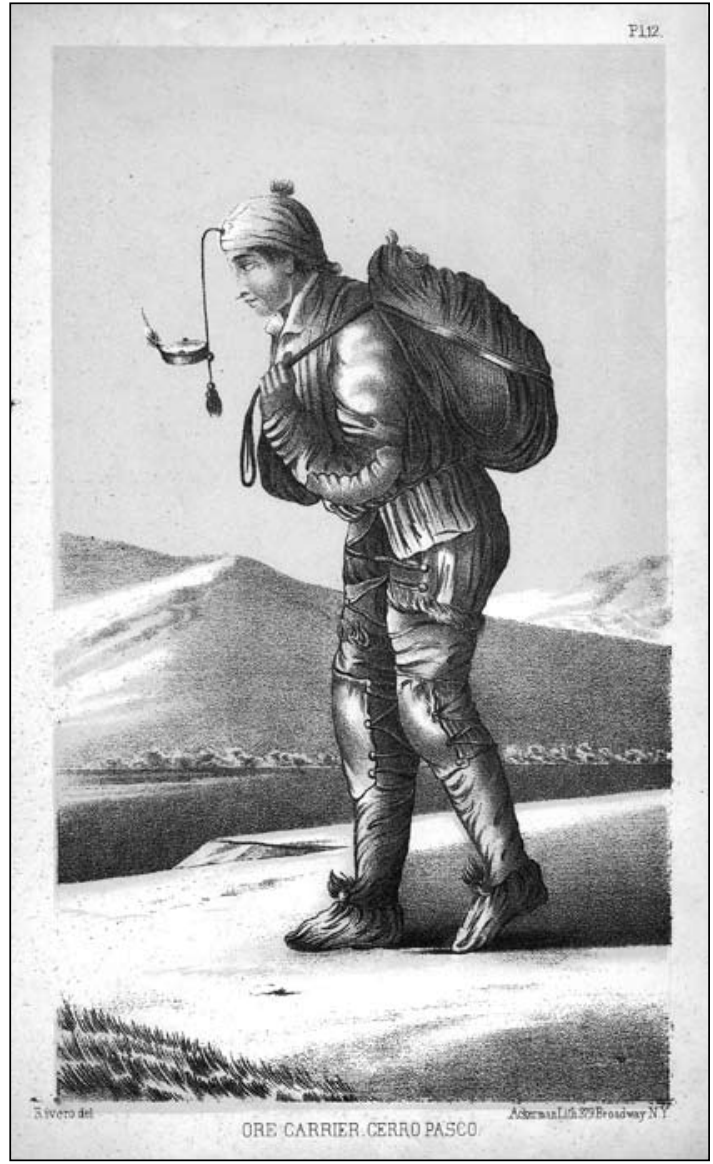

Figura 5. Apiri, cargador de minerales en Cerro Pasco, Perú. Tomado de Vicuña Mackenna (1883).

que se escoge a menudo a mano o se lava en maritatas, especie de harnero de poco más de $1 \mathrm{~m}$ de largo, que se sumerge con ímpetu repetidas veces en un estanque o cajón grande con agua, para aconchar el metal, quedando la broza en la superficie (1883: 218-219).

Para Cobija, Cajías (1975:345) señala que en la primera mitad del siglo XIX los mineros reciben "un cajón de metal por tres barreteros en seis días, ganan 12 reales por mita o jornal; 27 pesos; un prociri ${ }^{29}$ en seis días a peso diario, 6 p.; un pallir ${ }^{30}$ por lo mismo seis pesos más... dos fundidores a medio peso". En San José del Abra, Valdés (1886:42) constata que a fines de ese siglo: “El peón

\footnotetext{
29 No se ha encontrado referencia a este nombre en los diccionarios.

30 Palliri (quechua): mujer que se dedica a pallar, esto es, escoger el mineral rico y desechar la ganga (Diccionario Minero).
} 
de cancha cuesta 2 pesos al día; i el barretero trabaja por 20025 pesos el metro de labor, con todo gasto por su cuenta, excepto el acero y la lámpara".

Usualmente, en la segunda mitad del siglo XIX se usaba la "ficha-salario" como dinero alternativo, que después fuera popularizada en la industria del salitre. Este sistema fue introducido por la casa Artola para sus establecimientos, entre los que estaban los de Gatico (Cobija) y San Bartolo. Las fichas y vales emitidos por este sistema "circulaban desde las covaderas al altiplano". Hacia 1882 aún corrían fichas de ebonita con el anagrama de la empresa, y en su reverso el valor en mercaderías y la leyenda "Establecimiento de Gatico". Al parecer, la firma Artola también se vio involucrada en el tráfico de chinos "culíes" que trabajaban en estos establecimientos, junto a braceros changos de la costa y aymaras del altiplano (Núñez 2003).

Los hermanos Juan y Roberto Walker en Huasco, ya en los inicios del siglo XIX habían creado un sistema de dinero alternativo en billetes emitidos por ellos para fines de crédito, el que seguramente estuvo vigente en sus instalaciones de San Bartolo y Cobija. Este recurso, absolutamente ilegal, fue suspendido por un decreto del Gobierno (Núñez 2003). En Cobija, se fundó en 1870 una sucursal del Banco Nacional de Bolivia precisamente con la finalidad de movilizar el dinero legal y desterrar estas prácticas.

No nos hemos referido a la procedencia de los mineros que trabajaban en Atacama. Es conocido que el fenómeno de la minería, hasta hoy, es el que probablemente provoca más migraciones. Vidal Gormaz (1879: 13) señala que en San Bartolo trabajaban "más de 200 peones, la mayor parte chilenos", en momentos en que la Provincia de Atacama pertenecía a Bolivia. Seguramente en San Bartolo y Cobija laboraban obreros y empleados de diversas procedencias (Chile, Bolivia y Argentina), así como también trabajadores de esas localidades. Sin embargo, nos interesa el fenómeno de la migración de poblaciones andinas, por sus especiales características de movilidad, acreditadas desde épocas muy tempranas.

La industria minera involucraba a cientos de personas y actividades. No solamente a los pirquineros, operarios a jornal (barreteros o apires, llenadores, chancadores y carretilleros), sino también a personal administrativo de las minas, los arrieros y cargadores encargados del transporte. ${ }^{31}$ Todas estas actividades proporcionaban trabajo a las comunidades indígenas del sector (Calama, Chiu Chiu, Río Grande y San Pedro de Atacama), las que debieron aumentar la crianza de animales de carga y las áreas cultivadas para alimentar a los establecimientos mineros y para talaje. En San Bartolo está acreditado este hecho. ${ }^{32}$ Es así como las poblaciones indígenas locales entraron dentro de un sistema socioeconómico diferente de su modo de vida tradicional, pasando a ser transitoriamente asalariados, dentro de una economía monetaria. Sin embargo, ellos probablemente nunca perdieron sus vinculaciones con sus comunidades de origen y aprovechaban estas actividades para procurarse algún dinero, continuando con su sistema original de vida. Las mujeres también trabajaban en las minas como operarias (palliri), escogiendo en las canchas los minerales ricos y desechando la ganga. En antiguas fotografías de una mina en Chañarcillo (Figura 6) se puede ver en este proceso a mujeres andinas que bajaron del altiplano a servir estas funciones. Cajías, por su parte, registra los pagos que recibían las palliri en Cobija (1975:345).

Otro tanto ocurrió en la costa de Atacama, cuya población aumenta por migración de atacameños e indios de Paposo, atraídos por posibilidades de trabajo como changadores, arrieros y mineros. Al parecer éstos vivían en Gatico y estaban liderados por un cochabambino de apellido Maldonado, en algún momento durante la primera mitad del siglo XIX (Cajías 1975:328).

\footnotetext{
${ }^{31}$ Valdés (1886:42) señala que en San José del Abra "se paga actualmente 15 cts. por conducción de carga de subida, desde la cancha de las carretas hasta la mina i 20 cts. por bajada de un quintal métrico de minerales hasta el mismo punto". Añade que "el transporte de un quintal métrico de un artículo cualquiera desde Pampa Alta hasta el mineral vale 5 pesos i 2 pesos 80 cts. la conducción de $100 \mathrm{~kg}$ de minerales hasta aquella estación de ferrocarril; subiendo aún en 70 cts. el valor de un flete de un quintal para llegar a Antofagasta".

32 En la finca de Artola, en San Bartolo, había una superficie de unas 40 a 50 cuadras sembradas de alfalfa (Vidal Gormaz 1879: 13).
} 


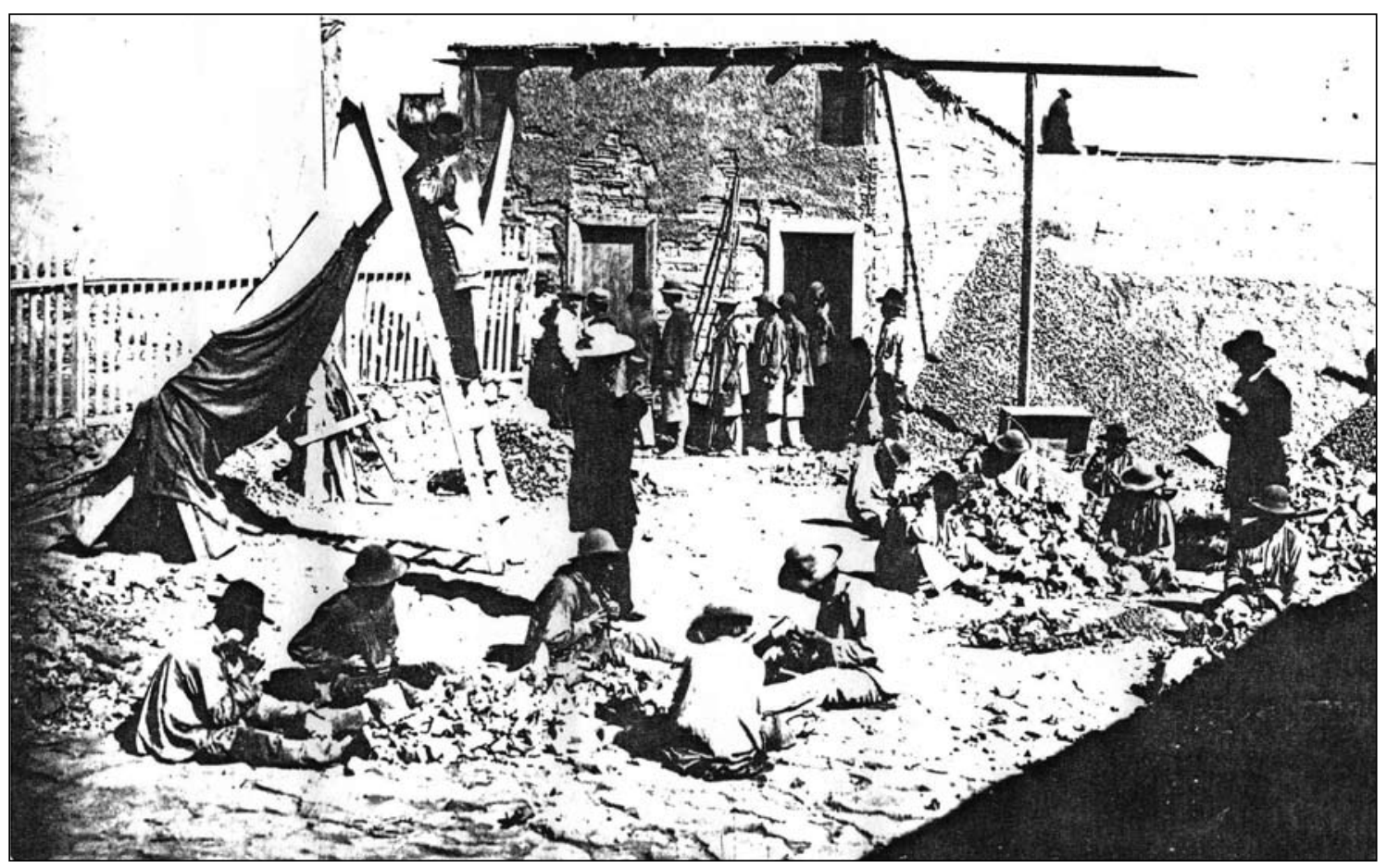

Figura 6. Palliris en Chañarcillo (1863). Expedición Científica Española. Placa de vidrio. Gentileza Dr. Francisco de Solano.

El traslado del metal durante el siglo XIX se hacía en carretas con tropas de mulares desde San Bartolo hacia Cobija, vía Calama y Chacance (Von Tschudi, en Lehnert 1996). ${ }^{33}$ La recolección superficial efectuada en los caminos asociados a esta ruta ha proporcionado una apreciable cantidad de herraduras de mulas. Como antecedente, Bowman (1940) señala que en Caracoles, en el apogeo de su actividad (1870), se empleaban regularmente 1500 carretas, cada una arrastrada por 5 a 6 mulas. Antes que las aguas se contaminaran con las aguas salinas de la quebrada de Palicaye, los animales de tiro tenían abundante talaje en el valle de San Bartolo, sobre todo en la parte superior. En Cobija el asunto era más serio, ya que los animales de carga no tenían talaje y debían partir de vuelta, apenas satisfecha la sed, el mismo día que descargaban (d'Orbigny 2002: 1033). Hemos apreciado que las rutas de estas arrierías entre la costa y Calama están literalmente sembradas de cadáveres de los animales de carga.

\footnotetext{
33 Después de los maremotos de la década de 1870 que destruyeron Cobija y construido el Ferrocarril de Antofagasta a La Paz, es probable que el traslado se hiciera usando esta vía hacia Antofagasta.
}

Las herraduras encontradas en San Bartolo también pueden explicarse por los caballares, mulares y también vacunos traídos para abastecer este establecimiento minero, a través de la cordillera, desde Argentina o Bolivia, los que eran herrados para soportar el viaje por la cordillera. Risopatrón observó vacunos pastando en el valle de San Bartolo:

"En Atacama hay mucho movimiento de animales, principalmente de ganado vacuno, pues es el puerto de entrada del ganado argentino con que se surte a Calama, los minerales adyacentes $i$ una parte de las salitreras del Toco $i$ de Pampa Alta. Se traen también algunos animales vacunos de Bolivia de Tarija, de cuyo lugar vi pastando algunos de gran talla en la finca Artola" (Risopatrón 1910: 136).

Philippi aporta un dato interesante al respecto, en su viaje por el Desierto de Atacama realizado en 1852. Observa que los atacameños continuaban la tradición de bajar a la costa en busca de pescado, y al mismo tiempo resalta que la actividad minera en la costa era de tal envergadura a mediados del siglo XIX, que los changos casi no pescaban, sino que se dedicaban a la minería. 
"Habiendo la guerra entre Perú y Bolivia hecho imposible el comercio entre Cobija y Atacama, estos indios (los atacamas) habian pensado emplear sus mulas en una expedición a Paposo para comprar por coca - el uso de mascar coca, tan general en Boliviay Perú, es igualmente esparcido entre los changos-, congrios y mariscos secos, y vender estos en las provincias argentinas. Llegados a la costa hallaron sin embargo sus esperanzas en gran parte frustradas, porque la mayor parte de los changos en vez de dedicarse a la pesca, habian preferido trabajar en las minas; los atacameños pues, habían podido comprar una cantidad pequeña de pescado" (Philippi 1860:23).

Las actividades mineras de la segunda mitad del siglo XIX exigieron a las comunidades indígenas de San Pedro de Atacama, Chiu Chiu y Calama abastecimientos agrícolas para proporcionar alimento y talaje de sus campos. Valdés señala que en Chiu Chiu esta demanda era tal que había encarecido los salarios de los peones locales "buenos pero escasos", a los que se pagaban 80 centavos diarios más 70 por su comida. Este hecho había provocado la contratación de peones:

\section{“(...) de Tupiza, Tolina, Moraya, Nazareno, Suipacha, Santiago} de Cotagaita i otros pueblecitos de la provincia de Chichas. Estos peones son todos de raza indígena pero más fuertes e inteligentes para el trabajo que los que se ocupan actualmente en Chiu Chiu y Calama. Se les da como alimento maíz, charqui $i$ harina de muño (morocho); i como salario tienen 70 centavos diarios" (Valdés 1886:183).

El sistema de transporte a través de la arriería también significó para las poblaciones atacameñas una fuente de ingresos. Para ellos, la adaptación a estas nuevas actividades debe haber sido sólo una extensión de su tradición de movilidad, por los circuitos de tráfico interregional preexistentes, a través del caravaneo, además de su conocimiento del paisaje y del modo de vida puneño. ${ }^{34}$

En el valle de San Bartolo hay restos de numerosas casas indígenas y de melgas de cultivo, que pudieron

\footnotetext{
34 De hecho, Valdés (1886: 182) señala que en Chiu Chiu había una población de alrededor de 500 personas que se dedicaban a la agricultura y a la arriería.
}

producir alfalfa abundante para el mantenimiento del ganado. Algunos riograndinos han confirmado que sus ascendientes trabajaban en labores de abastecimiento de la mina, como arrieros y/o abastecedores de talaje o productos agrícolas.

\section{$*$ CONCLUSIONES}

Los testimonios encontrados en San Bartolo y Cobija constituyen una evidencia más de que el modo de vida minero es propio de los pueblos andinos, los que han ejercido estas labores especializadas, junto con las tradicionales, en diferentes formas desde la prehistoria hasta hoy: sea con laboreos propios, como mitayos o asalariados de indígenas, españoles o de los extranjeros que iniciaron la gran minería en el siglo XX. Hoy, esta verdadera "cultura minera" indígena, se ha enseñoreado en el norte de Chile, sur de Bolivia y del Perú, siendo sus expresiones la adaptación a paisajes fuertes, frecuentemente inhóspitos, y vidas duras, la movilidad, producto de habitar enclaves diferentes, y las extraordinarias expresiones religiosas de los santuarios y festividades de las tierras altas y el desierto.

En el futuro, nos interesa profundizar la indagación acerca de la relevancia que la minería tuvo durante distintas épocas en las vinculaciones de las tierras altas con la costa. Pretendemos encontrar más restos arqueológicos a lo largo de los innumerables y laberínticos caminos, senderos y huellas que dejaron las recuas de mulas y carretas que surcaban el desierto, reflejos del intenso transporte de minerales y de la tradicional movilidad de los pueblos de Atacama.

Agradecimientos A nuestro compañero coinvestigador, el arqueólogo Patricio Núñez por su compañía e inapreciables aportes a esta investigación. Agrademos también la labor editorial, por sus valiosos comentarios. 


\section{* Referencias citadas}

ADÁn, L., 1999. Aquellos antiguos edificios. Acercamiento arqueológico a la arquitectura prehispánica tardía de Caspana. Estudios Atacameños 18: 13-34.

Aldunate, C., V. Castro y V. Varela, 2003. Oralidad y arqueología. Una línea de trabajo en las tierras altas de la región de Antofagasta. Chungara, Revista de Antropología Chilena 35 (2): 305-314.

- 2005. San Bartolo. Retazos de una historia de la minería en Atacama. Actas del XVI Congreso Nacional de Arqueología Chilena, pp. 213-225. Concepción.

2007 Ms. Camanchacas y atacamas en Cobija. Manuscrito en poder de los autores.

Alunni, A., 2006 Ms. A study investigating copper smeltings remains from San Bartolo, Chile. Submitted to the Department of Materials Science and Engeneering in Partial Fulfillment of the requirements for the Degree of Bachelor of Science at the Massachusetts Institute of Technology, Boston.

ARCE, I., 1997. Narraciones históricas de Antofagasta. Impreso en Lama Industrial, Antofagasta.

ARCE, R., 2003. Desarrollo económico e histórico de la minería en Bolivia. Plural Editores, La Paz.

Armas, J. C., s/f. Historia de Calama. Capital de la provincia El Loa. www.fotofiesta.cl (consultado el 23 Septiembre2005).

Berdichewsky, B., 1965. Exploración arqueológica en la costa de la provincia de Antofagasta. Antropología 3: 3-30.

Bermúdez, O., 1966. Orígenes históricos de Antofagasta. Editorial Universitaria, Santiago.

Bertrand, A., 1885. Memoria sobre las cordilleras del Desierto de Atacama y rejiones limítrofes. Imprenta y Litografía Antonio J. Escobar y Cía., Santiago.

BIRD, J., 1979. “The Copper Man”: A prehistoric miner and its tools from Northern Chile. En Precolumbian metallurgy of South America, E. Benson (Ed.), pp. 105-132. Dumbarton Oaks Research Library and Collections, Washington D. C.

BitTMAn, B., 1979. Cobija y alrededores en la época colonial (16001750). Actas del VII Congreso de Arqueología de Chile (1977), vol. 2, pp.327-364. Ediciones Kultrún, Santiago.

1983. Cobija: Panorama etnohistórico en relación a los informes del Dr. José Agustín de Arze. Chungara 10: 147-153. 1984a. Interrelaciones étnicas establecidas a lo largo de la costa del norte de Chile y sur del Perú en el contexto de la Colonia: Los camanchacas. Estudios Atacameños 7: 443-454.

1984b. El programa Cobija: Investigaciones antropológicomultidisciplinarias en la costa centro-sur andina; notas etnohistóricas. Contribuciones a los estudios de los Andes Centrales, S. Masuda (Ed.), pp. 101-149. Universidad de Tokio, Tokio.

— 1984c. El proyecto Cobija: Investigaciones antropológicas en la costa del Desierto de Atacama (Chile). XLIV Congreso Internacional de Americanistas (1982), pp. 99-146. Universidad del Norte, Antofagasta.

Bowman, I., 1940. Los senderos del Desierto de Atacama. Revista Chilena de Historia y Geografía. 97 y siguientes, Santiago.

Bravo, C. G., 2000. La flor del desierto: El mineral de Caracoles y su impacto en la economía chilena. Colección Sociedad y Cultura, Dirección de Bibliotecas, Archivos y Museos y LOM Ediciones, Santiago.

BRÜGGEN, J., 1946. Geología y morfología de la Puna de Atacama. Imprenta Universitaria, Santiago.

CAJíAs, F., 1975. La provincia de Atacama, 1825-1842. Instituto Boliviano de Cultura, La Paz.

Cañete y Domínguez, P., 1952 [1787]. Guía de la provincia de Potosí. Colección de la Cultura Boliviana, Editorial Potosí, Potosí.

CAstro, V., 1992. Nuevos registros de la presencia Inca en el Loa Superior. Gaceta Arqueológica Andina VI (21): 139-154.

1997. Huacca muchay. Evangelización y religión andina en Charcas, siglo XVI Atacama la Baja. Tesis de Magíster en Etnohistoria, Departamento de Antropología, Universidad de Chile, Santiago.

Comisión Chilena de Limites, 1907. Cartografía, Santiago.

Cruz, J. y L. Bravo, L., 1980. Cobija Sur-1. Sitio de ocupación temprana en la costa de Cobija, II Región, Chile. En: Cobija: Proyecto de investigaciones multidisciplinarias en la costa centro-sur andina (Chile), vol. 1, pp. 153-173. Departamento de Arqueología, Universidad del Norte, Antofagasta.

DicCionario de LA REALACADEMIA ESPAÑOLA DE LA LENGUA, 1972.

DicCIONARIO MINERO, 17 julio 2007-07-17Millallagua. www.http // español.geocities.com/mi_llallagua/diccionario.p.htm

Dомеуко, I., 1897. Mineralogía. Imprenta Cervantes, Santiago. 
1898. Tratado de ensayes, tanto por la vía seca como por la vía húmeda. Imprenta Cervantes, Santiago.

D'orbigny, A., 2002. Viaje a la América meridional (1826-1833). Instituto Francés de Estudios Andinos, La Paz.

FIfER, V., 1975. Bolivia. Editorial Francisco de Aguirre, Santiago.

Frezier, A. F., 1716. Relation du voyage de la merdu sud aux cotes du Chili et du Pérou, fait pendant les années 1712, 1713 \& 1714 . Imprenta de Jaques Quillau, París.

Graffam, G., A. Carevic y M. Rivera, 1995-1996. Evidencias metalúrgicas de fundición de cobre en el sitio Formativo Tardío de Ramaditas, quebrada de Guatacondo, provincia de Iquique, Chile. Estudios Atacameños 12: 53-67.

Herrman, A., 1900. Estado de la minería de cobre en Chile. Imprenta Universo, Santiago.

LARRAín, H., 1966. Contribución al estudio de una tipología cerámica encontrada en los conchales de Antofagasta. Anales de la Universidad del Norte, pp. 83-128. Antofagasta.

Latcham, R., 1927. La alfarería de los antiguos atacameños. Revista Universitaria Año XII, (5): 560-589.

1928. La prehistoria chilena. Sociedad Imprenta y Litografía Universo, Santiago.

1936. Metalurgia atacameña. Objetos de cobre y bronce. Boletín del Museo Nacional de Historia Natural, T XV.

_ 1938. Arqueología de la región atacameña. Prensas de la Universidad de Chile, Santiago.

LEHNERT, R., 1996. Johann Jacob von Tschudi: Su paso por el Desierto de Atacama. Texto y notas. Hombre y Desierto 10: 7-22.

Llagostera, A., 1979. Ocupación humana en la costa norte de Chile asociada a peces local extintos y a litos geométricos. Actas del VII Congreso de Arqueología de Chile (1977), pp. 93-113. Editorial Kultrún, Santiago.

1989. Caza y pesca marítima (9000 a 1000 AC). En Culturas de Chile. Prehistoria, J. Hidalgo, V. Schiappacasse, H. Niemeyer, C. Aldunate e I. Solimano (Eds.), pp. 57-80. Editorial Andrés Bello, Santiago.

2005. Culturas costeras precolombinas en el norte chileno: Secuencia y subsistencia de las poblaciones arcaicas. En Biodiversidad marina:Valoración, usos y perspectivas. ¿Hacia dónde va Chile?, E. Figueroa (Ed.), pp.107-148. Programa de Biodiversidad, Universidad de Chile. Editorial Universitaria, Santiago.
Molina, R., 2000 Ms. Informe sobre los títulos de dominio de la comunidad de Río Grande.

Moragas, C., 1982. Túmulos funerarios en la costa sur de Tocopilla (Cobija)-II Región. Chungara 9: 152-173.

NúÑEZ, L. y T. Dillehay, 1979. Movilidad giratoria, armonía social y desarrollo en los Andes Meridionales: Patrones de tráfico e interacción económica. (Ensayo). Universidad del Norte, Antofagasta.

NúÑEZ,L., 1999. Valoración minero-metalúrgica circumpuneña: Menas y mineros para el Inka rey. Estudios Atacameños 18: 177-207.

NúÑEZ, J., 2003. ¿Dinero alternativo o circulante de ilusiones?, Revista Mapocho 54: 53-77.

Palliere, L., 1945. Diario de un viaje por América del Sud 1856-1866. Ediciones Peuser, Buenos Aires.

Philippi, R., 1860. Viage al Desierto de Atacama. Hecho por orden del Gobierno de Chile en el verano 1853-54. Halle, Sajonia.

Risopatrón, L., 1910. La línea de la frontera con la República de Bolivia. Soc. Imprenta y Litografía Universo, Santiago.

1919. Diario de viaje a las cordilleras de Antofagasta y Bolivia (1903-1904). Revista Chilena de Historia y Geografía 28.

1924. Diccionario Geográfico de Chile. Imprenta Universitaria, Santiago.

SALAZAR, D., 2002. El complejo minero San José del Abra, II región (ca. 1450-1536 DC): Una aproximación a la arqueología de la minería. Tesis para optar al título de Magíster en Arqueología. Departamento de Antopología, Universidad de Chile, Santiago.

2003-2004. Arqueología de la minería: Propuesta de un marco teórico. Revista Chilena de Antropología 17: 125-150.

SalazAr, D., D. Melero y C. Jiménez, 2004. Los últimos 200 años en Conchi Viejo y San José del Abra (II región): Reflexiones sobre arqueología histórica y etnografía. Actas del XVI Congreso Nacional de Arqueología Chilena, pp. 227-238. Concepción.

SAN RomÁn, F., 1894. Reseña industrial e histórica de la minería y metalurgia de Chile. En Publicaciones de la exposición de minería y metalurgia de Santiago en 1894, Santiago.

1896. Desierto y cordilleras de Atacama. Imprenta Nacional, Santiago.

Schaedel, R., 1957. Arqueología chilena. Contribuciones al estudio de la región comprendida entre Arica y La Serena. Centro de Estudios Antropológicos. Universidad de Chile, Santiago. 
VALDÉs, S., 1886. Informe sobre el estudio minero i agrícola de la rejión comprendida entre el paralelo 23 i la Laguna de Ascotán. Imprenta Nacional, Santiago.

VARELA, V., 1992. De Toconce, pueblo de alfareros a Turi, pueblo de gentiles. Un estudio de etnoarqueología. Tesis para optar al Título profesional de arqueóloga. Departamento de Antropología, Universidad de Chile, Santiago.

VArela, V., M. Uribe y L. AdÁn, 1993. La cerámica arqueológica del sitio Pukara de Turi: 02-Tu-002. Boletín del Museo Regional de la Araucanía 4, vol. 2, pp. 107-121.
VARela, V., M. López y P. NúÑEZ, 2004 Ms. Tipos de lozas en sitios del camino. Informe interno Proyecto FONDECYT 1011006, Santiago.

Vicuña Mackenna, B., 1883. El libro del cobre i del carbón de piedra en Chile. Editorial del Pacífico, Santiago.

Vidal Gormaz, G., 1879. Noticias del desierto y sus recursos. Oficina Hidrográfica de Chile. Imprenta Nacional, Santiago.

Vivallo, W. y F. Henríquez, 1998. Génesis común de los yacimientos estratoligados y vetiformes de cobre del Jurásico Medio a Superior en la Cordillera de la Costa, región de Antofagasta, Chile. Revista Geológica de Chile 25 (2): 199-228. 